\title{
PSA Level Greater than Four
}

National Cancer Institute

\section{Source}

National Cancer Institute. PSA Level Greater than Four. NCI Thesaurus. Code C147088.

A blood concentration of prostate specific antigen greater than $4 \mathrm{ng} / \mathrm{mL}$. 